СОЛНЕЧНАЯ АКТИВНОСТЬ И ИЗМЕНЕНИЕ КЛИМАТА ЗЕМЛИ В ЭПОХУ ОКОНЧАНИЯ ЛЕДНИКОВОГО ПЕРИОДА И ПЕРЕХОДА К ГОЛОЦЕНУ

\author{
Кудрявцев И.В. ${ }^{1,2}$, Дергачев В.А. ${ }^{1}$ \\ ${ }^{1}$ Физико-технический институт им. А.Ф. Иоффе, Санкт-Петербург, Россия \\ ${ }^{2}$ Главная (Пулковская) астрономическая обсерватория РАН, Санкт-Петербург, Россия
}

\title{
SOLAR ACTIVITY AND EARTH'S CIMATE GHANGE IN THE EPOCH OF THE END OF THE ICE AGE AND THE TRANSITION TO THE HOLOCENE
}

\author{
Kudryavtsev I.V., ${ }^{1,2}$, Dergachev V.A. ${ }^{1}$ \\ ${ }^{1}$ Ioffe Institute, St. Petersburg, Russia \\ ${ }^{2}$ Central Astronomical Observatory of RAS, St. Petersburg, Russia
}

The possible connection of climate changes occurring during the end of the last ice age with changes in solar activity is considered. The results of reconstruction of the heliospheric modulation potential based on data on the content of the cosmogenic isotope ${ }^{10} B e$ in the ice layers from Greenland Ice Sheet are presented. Comparison of reconstructions of the heliospheric modulation potential based on ${ }^{14} \mathrm{C}$ and ${ }^{10} \mathrm{Be}$ data and paleoclimatic data is submitted. There are indications that the Meindorf warming may have been caused by high solar activity, and the Younger Dryas may have been the result of reduced solar activity.

\section{DOI: 10.31725/0552-5829-2020-189-192}

\section{1. Введение}

Известно, что основной вклад в генерацию космогенных изотопов в атмосфере Земли вносят частицы Галактических Космических лучей (ГКЛ), которые модулируются в межпланетном космическом пространстве солнечной активностью (СА). Это позволяет изучать активность Солнца в прошлом, в частности на основе данных по содержанию изотопа ${ }^{10} \mathrm{Be}$ в слоях льда Гренландии и Антарктиды, а также на основе радиоуглеродных данных. Изотопы ${ }^{10} \mathrm{Be}$ осаждаются из атмосферы и фиксируются в слоях льда ледников полярных зон, что позволяет измерять их концентрацию в слоях льда в момент их формирования. Изотопы ${ }^{14} \mathrm{C}$ участвуют в углеродном обмене между атмосферой, биосферой, океаном и гумусом. Поэтому климатические изменения приводят к перераспределению углерода между природными архивами и отражаются в радиоуглеродных данных. В данной работе рассматривается СА в эпоху окончания последнего глобального оледенения и перехода к Голоцену. Максимум последнего глобального оледенения имел место около 20 тысяч лет назад. На рисунке 1а приведена реконструкция глобальной температуры приземного слоя воздуха в рассматриваемый период [1,2]. Согласно данной реконструкции, рост глобальной температуры резко ускорился около 13000 гг. до н.э. Около 11500 
гг. до н.э. температура достигла локального максимума, после чего она начала уменьшаться. Около 10700 гг. до н.э. глобальная температура достигла минимума, а после этого росла до наступления Голоцена. На рисунке 16 приведены данные по изменению содержания изотопа ${ }^{18} \mathrm{O}$ в слоях льда Гренландии, которые отражают температуру слоёв льда в год их образования.

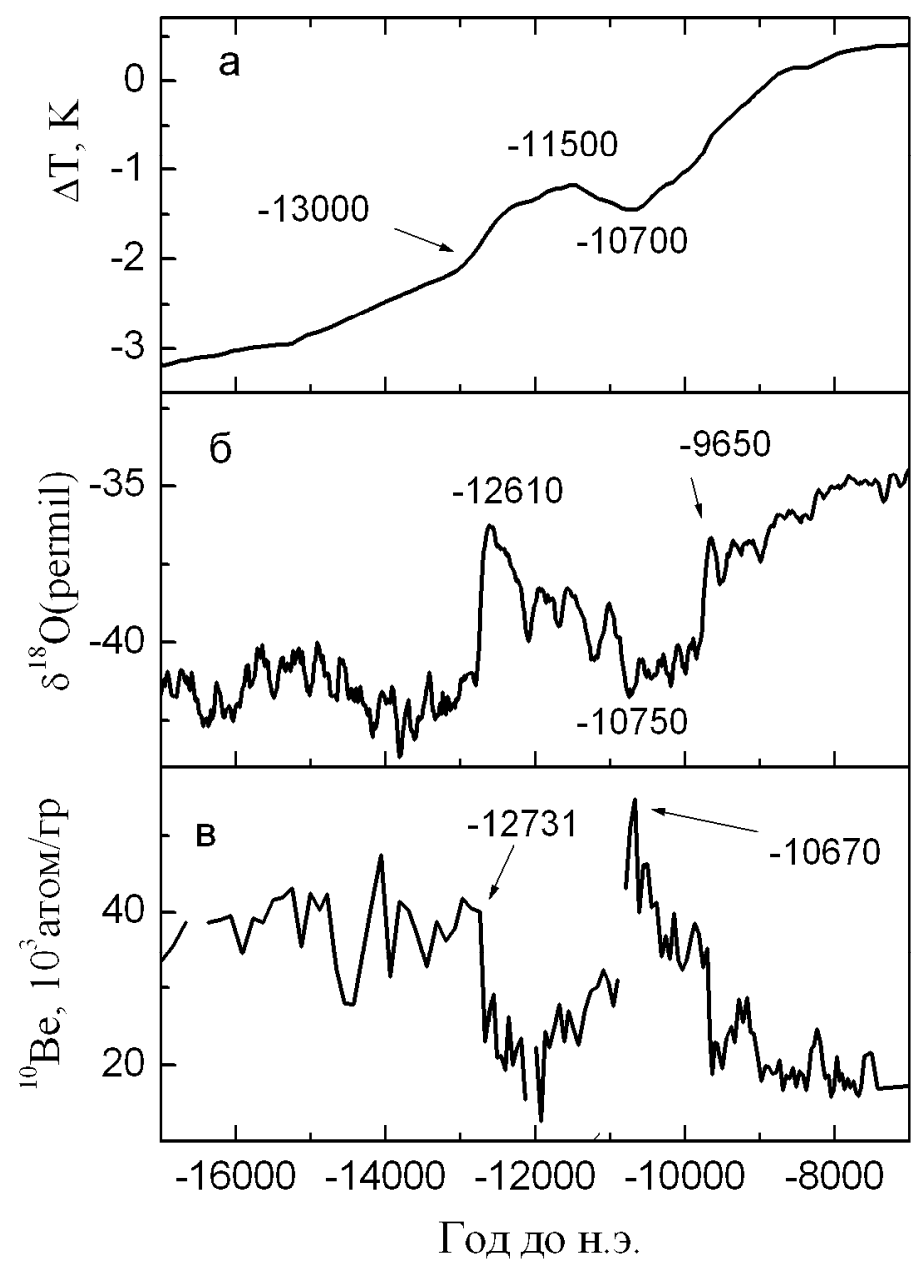

Рис. 1. (a) - изменение глобальной температуры согласно [1, 2]; (b) - изменение содержания изотопа ${ }^{18} \mathrm{O}$ во льдах Гренландии [3]; (c) - концентрация изотопа ${ }^{10} \mathrm{Be}$ во льдах Гренландии [4].

Этот рисунок показывает, что около 12800 гг. до н.э. произошло резкое увеличение температуры в Гренландии, около 12600 гг. до н.э. она достигла локального максимума и начала уменьшаться. Около 10750 гг. до н.э. содержание этого изотопа (и температура в Гренландии) достигли минимума. Между 12600 и 10750 гг. до н.э. происходили уменьшения и увеличения температуры.

Здесь необходимо отметить, что в интервале 12500-11850 гг. до н.э. на Земле происходило Майендорфское потепление. После этого происходил ряд похолоданий, самым длительным из которых является Поздний Дриас ( $~ 10700-9700$ гг. до н.э.). На рисунке 1в приведены данные по кон- 
центрации изотопа ${ }^{10} \mathrm{Be}$, отражающие вариации активности Солнца в прошлом. Этот рисунок показывает, что во время Майендорфского потепления происходило уменьшение содержания ${ }^{10} \mathrm{Be}$ во льду Гренландии, и оно достигло максимума к началу Позднего Дриаса.

\section{2. Реконструкции гелиосферного модуляционного потенциала}

На рисунке 2а приведены результаты реконструкции гелиосферного модуляционного потенциала $\varphi$ на основе этих данных по концентрации ${ }^{10} \mathrm{Be}$ во льду Гренландии. Реконструкция $\varphi$ проведена согласно работам $[5,6]$. При этом принималась пропорциональная зависимость между скоростью образования изотопа ${ }^{10} \mathrm{Be}$ в атмосфере $\mathrm{Q}\left(\right.$ атом $\left./\left(\mathrm{cm}^{2} \mathrm{c}\right)\right)$ и концентрацией изотопа азота в слоях льда $\mathrm{N}$ (атом/г). Как видно из рисунка, максимального значения $\varphi$ (а следовательно и СА) достигал около 12000 гг. до н.э., то есть во время Майендорфского потепления. Минимум $\varphi$ и СА около 10700 гг. до н.э. совпадает с Поздним Дриасом. Такое совпадение указывает на то, что и Майендорфское потепление и Поздний Дриас могут быть связаны с вариациями активности Солнца.

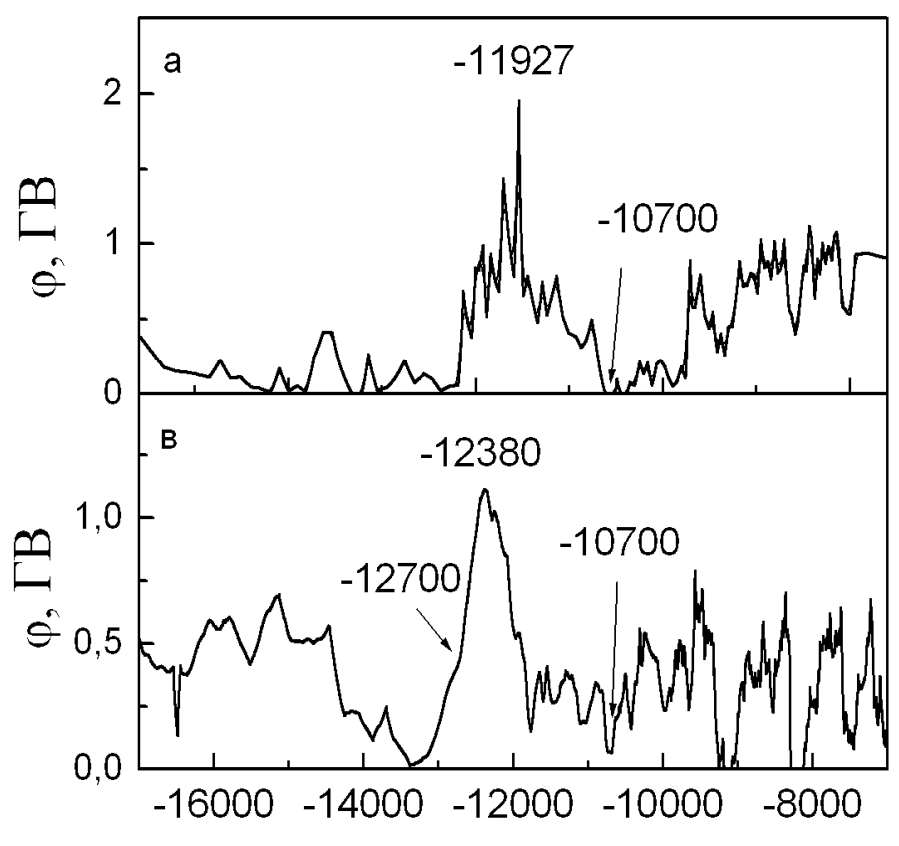

Год до н.э.

Рис. 2. Реконструированные значения модуляционного потенциала $\varphi$ на основе данных по концентрации изотопа ${ }^{10} \mathrm{Be}$ во льду Гренландии [4] (a) и на основе радиоуглеродных данных (в) [7].

На рисунке 26 приведены результаты реконструкции гелиосферного модуляционного потенциала $\varphi$ на основе радиоуглеродных данных согласно нашим работам $[8,9]$. Эта реконструкция учитывает влияние изменения климата на обмен изотопом ${ }^{14} \mathrm{C}$ между природными резервуарами, в частности, на изменение скорости перехода углерода из океана в атмосферу 
при изменении глобальной температуры. Из анализа этого рисунка следует, что во время Майендорфского потепления также достигается максимальное значение $\varphi$, которое может быть сравнимо с максимальными значениями в современную эпоху, а около 12380 гг. до н.э. значение $\varphi$ могло превышать 1ГВ. При этом солнечная активность в течение сотен лет держалась на высоком уровне и оставила след в данных как по содержанию космогенного изотопа ${ }^{10} \mathrm{Be}$ слоях льда полярных областей, так и изотопа ${ }^{14} \mathrm{C}$ в кольцах деревьев. В реконструкции модуляционного потенциала на основе радиоуглеродных данных также присутствует минимум около 10700 гг. до н.э., который соответствует Позднему Дриасу.

Среди минимумов гелиосферного модуляционного потенциала, а следовательно, и активности Солнца, необходимо выделить временные интервалы около 10700, 9100, 8200, 7500 гг. до н.э. Длительность этих минимумов превышала 100 лет. Рисунок 2в также показывает, что на временных интервалах 13600-13000 гг. до н.э. солнечная активность была очень низкой.

\section{3. Выводы}

Отметим основные результаты работы. Реконструкции гелиосферного модуляционного потенциала указывает, что на временных интервалах около 7500, 8200, 9100, 10700 гг. до н.э. Солнце находилось в состоянии глубоких минимумов активности. При этом длительность этих минимумов составляла сотни лет. Кроме того, на временном интервале 13600-13000 гг. до н.э. солнечная активность могла быть также низкой. Приведенные реконструкции показывают, что приблизительно в 12500-12000 гг. до н.э. активность Солнца была чрезвычайно высокой и такая высокая СА могла быть причиной Майендорфского потепления. В заключение отметим, что данные выводы сделаны на основе анализа двух независимых рядов данных.

Работа частично поддержана грантами РФФИ 18-02-00583 и 19-00088.

\section{Литература}

1. Shakun J.D. et al. // Nature, 2012, V. 484, P. 49.

2. Marcott S.A. and Shakun J.D. // Pages Magazine, 2015, V. 23, P. 28.

3. Cuffey K. M. et al. //Science, 1995, V. 270, P. 455.

4. Finkel R.C. and Nishiizumi K.J. // Geophys. Res., 1997, V. 102, P. 26699.

5. Kovaltsov G. A. et al. // Earth Planet. Sci. Lett., 2012, V. 337-338, P. 114.

6. Poluianov S.V. et al. // J. Geophys. Res.: Atmos., 2016, V.121, P. 8125.

7. Reimer P. J. et al. // Radiocarbon, 2013, V.55, P.1869.

8. Kudryavtsev I.V. and Dergachev V.A. // Proc. of Russian annual conf. "Solar and solarterrestrial physics - 2018" (St.-Petersburg, October 8-12, 2018) ed. A.V. Stepanov and Yu. A. Nagovitsyn (St.-Petersburg: Central Astronomical Observatory of RAS), 2018, P. 251.

9. Kudryavtsev I.V. and Dergachev V.A. // Geomagnetism and Aeronomy, 2019, V. 59, P. 1099. 